\title{
Chain-Length Shortening of Methyl Ethyl Hydroxyethyl Cellulose: An Evaluation of the Material Properties and Effect on Foaming Ability
}

\author{
Kristina Karlsson $^{1}$ (D) Marc Carrillo Aguilera ${ }^{1} \cdot$ Leif Karlson $^{2} \cdot$ Mats Stading $^{1,3} \cdot$ Mikael Rigdahl $^{1}$
}

Published online: 16 August 2018

(c) The Author(s) 2018

\begin{abstract}
During the past century, plastics have become a natural element in our every-day life. Lately however, an awareness about the fossil origin and often non-degradable nature of many plastics is rising. This has resulted in the emergence of some bio-based and/or biodegradable plastics, often produced from renewable resources. One possible candidate for bioplastics production could be found in cellulose. This paper aims at contributing information regarding a cellulose derivative, which could possibly be used in foamed plastics applications. Therefore, the reduction of the chain-length of a methyl ethyl hydroxyethyl cellulose (MEHEC), assessed by size exclusion chromatography, and the effect of chain-length on the foaming behaviour were studied. The foaming was accomplished with a hot-mould technique using aqueous polymer solutions. The generated steam was here used as the blowing agent and important parameters were polymer concentration and solution viscosity. The density of the produced foams was assessed and was in some cases comparable to that of commodity foams. It was found that reducing the chain-length enabled an increase of the initial polymer concentration for the foaming process. This is believed to be beneficial for creating more structurally stable foams of this type.
\end{abstract}

Keywords Methyl ethyl hydroxyethyl cellulose (MEHEC) · Cellulose derivatives · Chain-length shortening · Foaming · Rheology

\section{Introduction}

The plastic industry has been steadily growing since the 1950s and in 2015, 322 million metric tons of plastics were produced globally, a $3.4 \%$ increase from the year before [1]. The main reason for the rapid growth of this material as an indispensable engineering material is most likely the versatility [2]. Plastics are found in a range of applications, from low-cost disposable packaging to high-strength composite materials with applications in the auto- and aero-industry.

Kristina Karlsson

kristina.karlsson@chalmers.se

1 Department of Industrial and Materials Science, Chalmers University of Technology, Rännvägen 2A, 41296 Gothenburg, Sweden

2 Product and Process Chemistry - Performance Additives, Akzo Nobel Functional Chemicals AB, 44430 Stenungsund, Sweden

3 Research Institutes of Sweden (RISE), Bioscience and Materials, PO Box 5401, 40229 Gothenburg, Sweden
They exist as flexible or rigid, lighter or denser and the price varies greatly depending on properties and applications.

Despite a flourishing industry, the negative effects of the extensive use of fossil fuels during the past century have begun to show, and this has favoured the emergence of some types of new, renewable and bio-based plastics. Even though some plastics with renewable origin are already established on the market today, e.g. cellulose acetate, poly(lactic acid) (PLA) and some starch based plastics, the available information and research activities on properties and processing of conventional plastics appear to be vastly greater. Cellulose is a natural polymer found in plants and is also produced by some bacteria and algae $[3,4]$ and it has great potential as an engineering material, being abundant, renewable and strong in relation to its weight [5]. Traditionally cellulose has been used as a construction material in the shape of wood, in papermaking and in the form of cotton for thousands of years, but more recently its full potential has been recognized. Cellulose has in fact only been used as a chemical raw-material for the past 150 years [6].

Structurally, cellulose is a polysaccharide built up from 1, 4-anhydroglucose units. Native cellulose forms large 
crystalline regions and is insoluble in water. Chemical modification can however yield water-soluble cellulose derivatives and an early example of this is the production of cellulose-ethers. These polymers are still used, for example, as consistency agents in building and drilling applications, in paints, and as rheology modifiers in pharmaceuticals and cosmetics. There is however still a need for an improved understanding of the structure-property relationships, especially when aimed for expanding the use of cellulose derivatives into new application areas [6].

An example of a possible application area for cellulose ethers would be as foamed or cellular polymers, which constitutes a group of materials which has more recently gained an increased interest due to their low weight and possible fuel savings during transportation. This forms the basis for the present work which aims at investigating the possibility to use an ethyl hydroxyethyl cellulose (EHEC), or more specifically, the methyl ethyl hydroxyethyl cellulose (MEHEC) for foaming applications.

The possibility of foaming cellulose derivatives using water (steam) as the blowing agent has previously been investigated and it was found that hydroxypropyl methylcellulose (HPMC) exhibited better foaming properties than MEHEC and EHEC when a hot-mould baking technique was used for the foaming [7]. One of the factors considered to be the reason for the poorer foamability of the EHEC samples was the difference in molecular chain length compared to the HPMCs. The larger molecular chain length of the EHEC was believed to cause the sample to gel strongly in water solutions at low polymer concentrations, hindering the steam-assisted expansion of a growing bubble. Karlsson et al. [7] noted that in case of HPMC, the storage modulus of the polymer solution was quite low at room temperature, allowing an expansion to take place as the water steam was formed as the temperature was increased. At the same time the storage modulus increased substantially with increasing temperature, stabilizing the final foam.

In order to assess if the chain length is an important factor for the forming of a stable foam of a MEHEC derivative, the polymer was subjected to a chain shortening treatment. The treated derivatives were characterized with regard to their molecular chain lengths and rheological properties and furthermore their foamability was assessed by the same hotmould technique previously used [7].

\section{Experimental}

\section{Materials}

MEHEC and sodium hypochlorite, $\mathrm{NaClO}$ 13\% (Fisher Scientific, US), were kindly supplied by AkzoNobel-Product and Process Chemistry, Stenungsund, Sweden. Some characteristics of the used MEHEC grade, as given by the manufacturer, are given in Table 1.

The EHEC ethers are non-ionic, amphiphilic, water-soluble polymers and they exhibit a clouding behaviour. Clouding is a macroscopic phenomenon, caused by the formation of aggregates, and is believed to be caused by a decrease in the dipolar character of the $\mathrm{C}-\mathrm{O}$ bond where the molecule becomes less and less polar with increasing temperature $[8$, 9].

\section{Methods}

\section{Preparation of Materials-Chain Shortening}

The general procedure for reducing the chain length (molecular weight) was as follows. Sodium sulphate, $\mathrm{Na}_{2} \mathrm{SO}_{4}$, which was used to promote the mixing of the components and to reduce the cloud point $[9,10]$ of the cellulose derivative was dispersed in one litre of deionized water and heated to $93{ }^{\circ} \mathrm{C}$ during stirring with a propeller mixer. Then $100 \mathrm{~g}$ of the MEHEC derivative was added. $\mathrm{NaClO}$, being the reducing agent was added last. The mixture was left stirring for $30 \mathrm{~min}$ and thereafter the slurry was filtered and dried in a vacuum oven, in nitrogen atmosphere, at $60{ }^{\circ} \mathrm{C}$ overnight.

Ten batches of modified MEHEC, using different reaction conditions to shorten the chain length, were prepared. The amount of water $(1 \mathrm{~L})$ and MEHEC $(100 \mathrm{~g})$ was kept constant. Five different amounts of $\mathrm{NaClO}$ was added: 0.5 , 1, 2, 4 and $8 \mathrm{wt} \%$ (relative to the MEHEC-content) and four different amounts of $\mathrm{Na}_{2} \mathrm{SO}_{4}: 0,20,50$ and $100 \mathrm{~g} / \mathrm{L}$ were used. In addition, a reference solution without any $\mathrm{NaClO}$ was prepared. Table 2 summarizes the different reaction conditions used.

\section{Preparation of Films}

Films for determination of the glass transition temperatures $\left(T_{g}\right)$ of the modified cellulose ethers were prepared by mixing $1 \%$ by weight of the polymer with deionised water. The mixing took place at $90{ }^{\circ} \mathrm{C}$, using a magnetic stirrer, for a few minutes until the mixture was homogenous. The solutions were poured into $85 \mathrm{~mm}$ diameter petridishes and were

Table 1 Characteristics of the MEHEC used, as provided by the manufacturer

\begin{tabular}{llll}
\hline Name & DS-ethyl & DS-methyl & MS-ethylene oxide \\
\hline MEHEC & 0.2 & 1.3 & 0.4 \\
\hline
\end{tabular}

Degree of substitution (DS) is the number of hydroxyl groups per 1,4-anhydroglucose unit which have been reacted. Molecular substitution (MS) is the average total number of ethylene oxide groups per 1,4-anhydroglucose unit 
Table 2 Amounts of added chemicals to the MEHEC-derivative during the chain shortening reaction

\begin{tabular}{lcl}
\hline Sample & $\mathrm{Na}_{2} \mathrm{SO}_{4}(\mathrm{~g} / \mathrm{L})$ & $\mathrm{NaClO}(\mathrm{wt} \%)$ \\
\hline 1 & 100 & 2 \\
2 & 50 & 4 \\
3 & 20 & 8 \\
4 & 20 & 4 \\
5 & 20 & 2 \\
6 & 20 & 1 \\
7 & 20 & 0.5 \\
8 & 20 & 0 \\
9 & 0 & 4 \\
10 & 0 & 1 \\
\hline
\end{tabular}

dried at room temperature for about 5 days yielding freestanding films.

\section{Molecular Weight Distribution}

A lowering of the solution viscosity (see below) indicates a reduction of the molecular weight of the polymer. Size exclusion chromatography (SEC) with triple detection (RI, viscosity and light scattering), was here used to confirm the chain shortening due to the treatment with $\mathrm{NaClO}$ and to determine the molecular weight distribution of some samples. A GPCmax instrument equipped with a tetra detection array TDA 302 (Malvern, UK), a pre-column and two TSK G3000PWXL gel columns (Tosoh Bioscience, Japan) was used. Solutions with concentrations of $0.5,1.0$ and $1.5 \mathrm{mg} /$ $\mathrm{mL}$ were prepared. The samples were shaken overnight and filtered over a $0.45 \mu \mathrm{m}$ regenerated cellulose filter (GE Healthcare). The detectors were calibrated using a pullulan standard (P-100, Shodex) [11, 12]. The mobile phase solvent consisted of a $0.05 \mathrm{M}$ sodium acetate $(13.6 \mathrm{~g} / 2 \mathrm{~L})$ and $0.02 \mathrm{wt} \%$ sodium azide $(0.4 \mathrm{~g} / 2 \mathrm{~L})$ adjusted to $\mathrm{pH} 6$ with acetic acid. The injection volume was $100 \mu \mathrm{l}$, the flow rate $0.5 \mathrm{ml} / \mathrm{min}$ and the temperature was $35^{\circ} \mathrm{C}$. The specific refractive index, $\mathrm{dn} / \mathrm{dc}$, was measured by two detectors at $7^{\circ}$ and $90^{\circ}$ and determined to be 0.148 .

\section{Viscosity Measurements}

Solutions for viscosity measurements were prepared by mixing $2 \mathrm{wt} \%$ of the polymer with deionized water at room temperature, the samples were left stirring for about $12-16 \mathrm{~h}$ to ensure a proper mixing. An ARES G2 (TA Instruments, USA) rotational rheometer with a cone-plate setup was used to measure the viscosity at shear rates in the range 0.01 and $100 \mathrm{~s}^{-1}$. The reported viscosity values were taken at the Newtonian plateau, at low shear rates. For the batches with a large added amount of $\mathrm{NaClO},(\geq 4 \mathrm{wt} \%)$ the measurements were in some cases repeated with a $5 \mathrm{wt} \%$ polymer concentration in order to increase the signal-to-noise ratio. Each measurement was repeated at least twice and sometimes up to four times to ensure a reproducible result. The variation in shear viscosity between the specimens was less than $15 \%$ (standard deviation).

\section{Cloud Point Determination}

For the cloud-point determinations, solutions with either 5 , 2 or $1 \mathrm{wt} \%$ polymer in deionized water were prepared. The solutions were transferred to capillary glass tubes, centrifuged and thereafter analysed spectrophotometrically by a Mettler FP90 (Mettler Toledo, USA). The temperature scan rate was $2{ }^{\circ} \mathrm{C} / \mathrm{min}$ and the scans were performed in an interval from 50 to $90{ }^{\circ} \mathrm{C}$.

\section{Dynamic Mechanical Thermal Analysis (DMTA)}

DMTA was employed in order to assess the $T_{g}$ of the freestanding films. Oscillatory measurements were carried out on a DMTA-instrument (Rheometrics Scientific RSA-II, USA) performed at a frequency of $1 \mathrm{~Hz}$, a strain amplitude of $0.05 \%$ and a heating rate of $5{ }^{\circ} \mathrm{C} / \mathrm{min}$. Temperature sweeps between 20 and $220{ }^{\circ} \mathrm{C}$ were performed.

\section{Hot-Mould Foaming}

Hot-mould foaming, or compression mould foaming, was here used to evaluate the foaming ability of the materials. The polymer, in form of a powder, was dispersed in water using a magnetic heated stirrer plate at $90{ }^{\circ} \mathrm{C}$. The polymer content was varied and solutions with concentrations of $5-20 \mathrm{wt} \%$ were prepared. The solution was poured into a circular mould with a diameter of about $25 \mathrm{~mm}$ and the mould was placed between the two heated plates of the press equipment (Franz Haas Waffelmaschinen, Austria). Upon closing the mould a slight pressure from the weight of the top plate was applied and the plate temperatures were varied between 160 and $220^{\circ} \mathrm{C}$ with moulding times of $10-15 \mathrm{~min}$.

\section{Density Measurements}

The densities of the produced foams were evaluated using two different techniques. If the foam had filled the mould completely and its cross-section was circular, the volume was estimated by measuring the diameter and height of the sample. The density was then obtained from the ratio between the sample weight and the measured volume. If the sample had not expanded and filled the mould properly, a somewhat irregular shape was obtained. The volume of the sample was then estimated using a sand-displacement method $[7,13]$ where the sample was immersed in sand in a 
measuring cylinder and the change in volume after tapping the cylinder was recorded. The weight was then divided by the volume to obtain the density.

\section{Optical Microscopy}

A surgical stainless-steel blade (Swann Morton, England) was used to cut the samples into slices. An optical microscope, SteREO Discovery.V20, (ZEISS, Germany) was used to study the foam structure.

\section{Environmental Scanning Electron Microscopy (ESEM)}

A surgical stainless-steel blade (Swann Morton, England) was used to cut samples into a suitable size. These samples were glued onto aluminium stubs using a carbon paste and then sputter coated (S150B Edwards Sputter Coater, Edwards, UK) with gold for 1 min under vacuum. Thin carbon glue lines were drawn on the samples to connect the conducting surfaces. The surface of the samples as well as their cross-section were studied using an XL-30 ESEM (Philips, Netherlands).

\section{Results}

\section{Chain Length Determination by SEC}

The chain length of some selected modified MEHECs was evaluated by SEC and the results are given in Table 3 in terms of their number average molecular weights $\left(M_{n}\right)$ and weight average molecular weights $\left(M_{w}\right)$. The unmodified MEHEC was used as a reference. A clear trend where an

Table $3 M_{n}$ and $M_{w}$ for eight MEHEC samples treated under different chain reducing conditions, determined by SEC

\begin{tabular}{|c|c|c|c|c|}
\hline Sample & Description & $\mathrm{M}_{n}(\mathrm{~g} / \mathrm{mol})$ & $\mathrm{M}_{w}(\mathrm{~g} / \mathrm{mol})$ & $\mathrm{PI}^{\mathrm{a}}$ \\
\hline MEHEC & Ref MEHEC (unmodified) & 57,300 & 373,600 & 6.5 \\
\hline 2 & $\begin{array}{l}50 \mathrm{~g} / \mathrm{L} \mathrm{Na}_{2} \mathrm{SO}_{4}, 4 \mathrm{wt} \% \\
\mathrm{NaClO}\end{array}$ & 14,800 & 55,300 & 3.7 \\
\hline 3 & $\begin{array}{l}20 \mathrm{~g} / \mathrm{L} \mathrm{Na}_{2} \mathrm{SO}_{4}, 8 \mathrm{wt} \% \\
\mathrm{NaClO}\end{array}$ & 14,600 & 35,000 & 2.4 \\
\hline 4 & $\begin{array}{l}20 \mathrm{~g} / \mathrm{L} \mathrm{Na}_{2} \mathrm{SO}_{4}, 4 \mathrm{wt} \% \\
\mathrm{NaClO}\end{array}$ & 16,800 & 55,400 & 3.3 \\
\hline 6 & $\begin{array}{l}20 \mathrm{~g} / \mathrm{L} \mathrm{Na}_{2} \mathrm{SO}_{4}, 1 \mathrm{wt} \% \\
\mathrm{NaClO}\end{array}$ & 32,700 & 152,500 & 4.7 \\
\hline 8 & $\begin{array}{l}20 \mathrm{~g} / \mathrm{L} \mathrm{Na}_{2} \mathrm{SO}_{4}, 0 \mathrm{wt} \% \\
\mathrm{NaClO}\end{array}$ & 50,700 & 381,700 & 7.5 \\
\hline 9 & $\begin{array}{l}0 \mathrm{~g} / \mathrm{L} \mathrm{Na}_{2} \mathrm{SO}_{4}, 4 \mathrm{wt} \% \\
\mathrm{NaClO}\end{array}$ & 24,600 & 57,700 & 2.3 \\
\hline 10 & $\begin{array}{l}0 \mathrm{~g} / \mathrm{L} \mathrm{Na}_{2} \mathrm{SO}_{4}, 1 \mathrm{wt} \% \\
\mathrm{NaClO}\end{array}$ & 55,400 & 132,200 & 2.4 \\
\hline
\end{tabular}

${ }^{\mathrm{a}} P I=M w / M n($ polydispersity index $)$ increasing addition of $\mathrm{NaClO}$ resulted in a reduced chain length (molecular weight) can be seen. For the samples with the same amount of added $\mathrm{NaClO}$, a similar $M_{w}$ was achieved. There was however a slight tendency for the $M_{n}$ to decrease when the amount of $\mathrm{Na}_{2} \mathrm{SO}_{4}$ was increased at a constant amount of the sodium hypochlorite. However, a more extensive study would be needed in order to confirm this trend.

To visualize the results further, Fig. 1 shows $M_{w}$ for eight of the samples. The $M_{w}$ can clearly be correlated to the amount of $\mathrm{NaClO}$ used. The reference material and sample 8 (no $\mathrm{NaClO}$ ) exhibited $M_{w}$-values in the same range. Samples 6 and 10 also had similar $M_{w}$ and were both reacted with an addition of $1 \mathrm{wt} \% \mathrm{NaClO}$. The same trend applies to samples 2, 4 and 9 with an addition of $4 \mathrm{wt} \% \mathrm{NaClO}$. The lowest $M_{w}$ was observed for sample 3 with the highest amount of added $\mathrm{NaClO} ; 8 \mathrm{wt} \%$. The decrease in $M_{w}$ was significantly larger between the samples with no $\mathrm{NaClO}$ and $4 \mathrm{wt} \%$ than the corresponding difference between 4 and $8 \mathrm{wt} \%$, indicating the existence of a saturation level.

\section{Viscosity of the Polymer Solutions}

As already stated in the Experimental section, the viscosity was measured at a polymer concentration of $2 \mathrm{wt} \%$. In some cases, the concentration was increased to $5 \mathrm{wt} \%$, but this had no significant effects on the general trend or the conclusions. In general, all the samples showed a shear-thinning behaviour, at least at higher shear rates $\left(>10 \mathrm{~s}^{-1}\right)$. At lower shear rates, the samples exhibited a Newtonian plateau and the viscosity values shown in Table 4 below are obtained from this plateau. The general observation was that a higher amount of added $\mathrm{NaClO}$ resulted in a lower viscosity which would correspond to a reduction in chain length (or molecular weight)

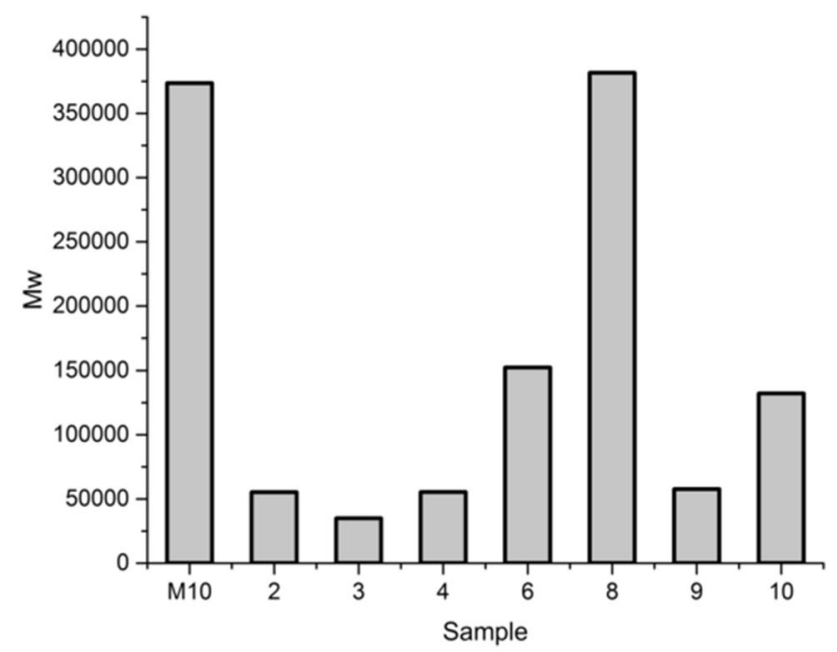

Fig. 1 The $M_{w}$ of the different samples shown in Table 3 
Table 4 Viscosities of the MEHEC solutions at the Newtonian plateau

\begin{tabular}{llrlc}
\hline Sample & $\mathrm{NaClO}(\mathrm{wt} \%)$ & $\mathrm{Na}_{2} \mathrm{SO}_{4}(\mathrm{~g} / \mathrm{L})$ & $M_{w}(\mathrm{~g} / \mathrm{mol})$ & $\begin{array}{l}\text { Viscosity } \\
(\mathrm{mPa} \mathrm{s})\end{array}$ \\
\hline 1 & 2 & 100 & - & 98 \\
2 & 4 & 50 & 55,290 & 22 \\
3 & 8 & 20 & 34,980 & 7 \\
4 & 4 & 20 & 55,380 & 10 \\
5 & 2 & 20 & - & 57 \\
6 & 1 & 20 & 152,460 & 536 \\
7 & 0.5 & 20 & - & 671 \\
8 & 0 & 20 & 381,670 & 763 \\
9 & 4 & 0 & 57,650 & 7 \\
10 & 1 & 0 & 132,180 & 107 \\
\hline
\end{tabular}

The polymer concentration was $2 \mathrm{wt} \%$

provided that the added amount of sodium sulphate was kept constant. This is also supported by the SEC measurements reported on in the previous section. The greatest reduction in viscosity was observed in the low range region of added $\mathrm{NaClO}$. The effect seems to be less pronounced when the amount of $\mathrm{NaClO}$ was increased, compare for instance the results obtained at $4 \mathrm{wt} \%$ (samples 2, 4 and 9) with those obtained at $8 \mathrm{wt} \%$ (sample 3 ). This is also paralleled by the change in $M_{w}$ as discussed above. The behavior is illustrated in Fig. 2 (left).

As shown in Fig. 2 (right), the added mixing aid sodium sulphate had a slight counteracting effect on the viscosity reduction caused by the addition of $\mathrm{NaClO}$. Here the sodium hypochlorite content was kept at $4 \mathrm{wt} \%$. This increase in viscosity cannot be attributed to a corresponding increase of the chain length, since the weight-average molecular weight was virtually unaffected by the amount of $\mathrm{Na}_{2} \mathrm{SO}_{4}$, cf samples 2, 4, and 9, and the number average $M_{n}$ even decreased somewhat when increasing the salt content. This would indicate that there are other reasons for the increase in viscosity than changes in the molecular weight or chain length. Joshi et al. thoroughly studied the effect of salt addition on the gelation behaviour of aqueous HPMC solutions [14]. The effect of the ions was attributed to their ability for water structuring rather than to a direct interaction between ions and the polymer chains. A lower number of water molecules available to solvate the polymers chains in the more ordered state consequently lowered the gelation temperature of the HPMC solutions. It was concluded that multivalent anions, such as $\mathrm{Na}_{2} \mathrm{SO}_{4}$ had a stronger reducing effect on the gelation temperature than monovalent anions such as sodium chloride $(\mathrm{NaCl})$. Furthermore, the rheological behaviour of the solutions was studied and an addition of $\mathrm{Na}_{2} \mathrm{SO}_{4}$ resulted in an increase of the storage modulus $\left(G^{\prime}\right)$ as the curve was shifted to lower temperatures [14], indicating that the gel was strengthened by the salt addition. A similar interaction between the salt and water is a possible explanation resulting in the observed viscosity increase in the present study.

\section{Cloud Point}

The measured cloud points of the ten different solutions and the reference solution are given in Table 5 below. For samples $1-5$ and 9 , a $5 \mathrm{wt} \%$ polymer concentration was used since these polymers had a lower molecular weight and hence a lower solution viscosity. For samples 6-8, 10 and the reference, a $2 \mathrm{wt} \%$ polymer concentration was used since the higher viscosity of these solutions made it difficult
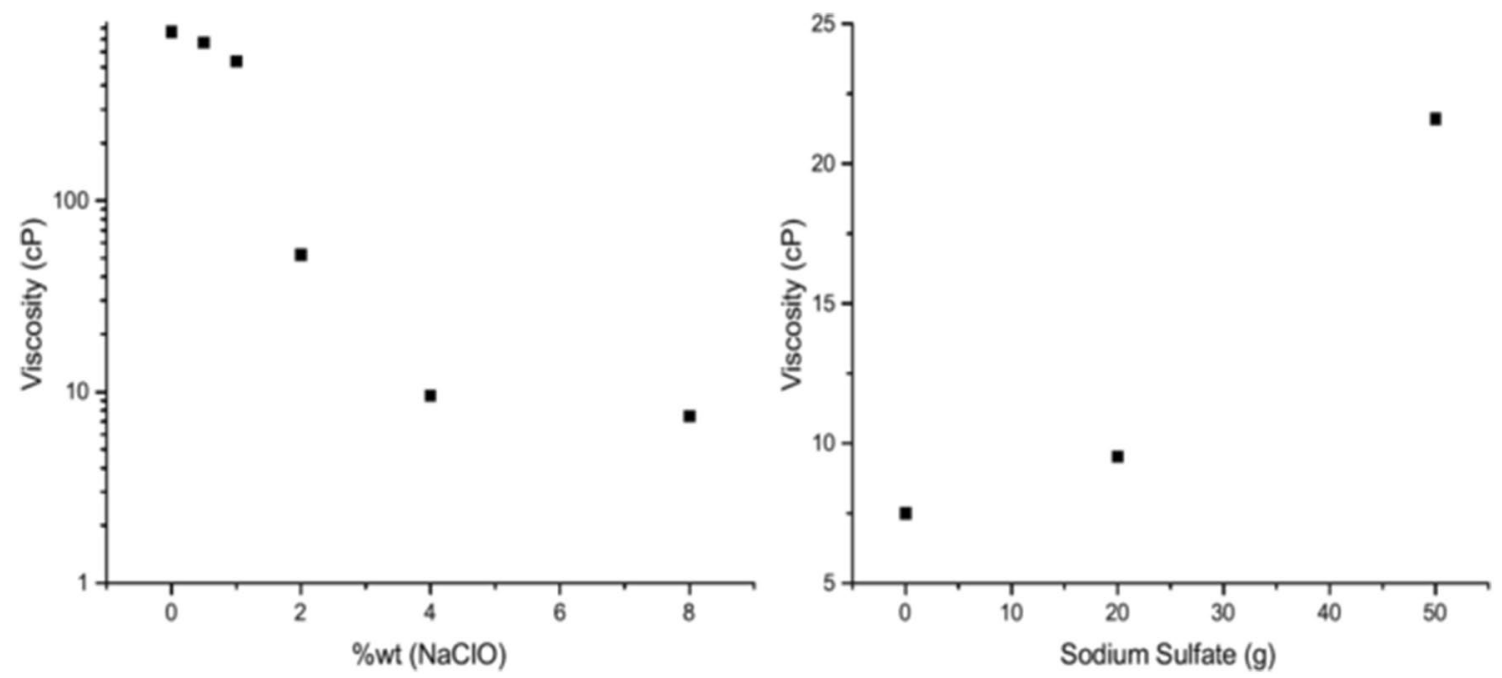

Fig. 2 To the left: viscosity at different concentrations of $\mathrm{NaClO}$ and $20 \mathrm{~g} / \mathrm{L}$ of $\mathrm{Na}_{2} \mathrm{SO}_{4}$. To the right: viscosity at different concentrations of $\mathrm{Na}_{2} \mathrm{SO}_{4}$ and $4 \mathrm{wt} \% \mathrm{NaClO}$ 
Table 5 Cloud points of the 11 MEHEC samples

\begin{tabular}{llllll}
\hline Sample & $\begin{array}{l}\mathrm{NaClO} \\
(\mathrm{wt} \%)\end{array}$ & $\begin{array}{l}\mathrm{Na}_{2} \mathrm{SO}_{4} \\
(\mathrm{~g} / \mathrm{L})\end{array}$ & $M_{w}(\mathrm{~g} / \mathrm{mol})$ & $\begin{array}{l}\text { Viscosity } \\
(\mathrm{mPa} \mathrm{s})\end{array}$ & $\begin{array}{l}\text { Cloud } \\
\text { point } \\
\left({ }^{\circ} \mathrm{C}\right)\end{array}$ \\
\hline 1 & 2 & 100 & - & 98 & 49 \\
2 & 4 & 50 & 55,290 & 22 & 64 \\
3 & 8 & 20 & 34,980 & 7 & 65 \\
4 & 4 & 20 & 55,380 & 10 & 65 \\
5 & 2 & 20 & - & 57 & 63 \\
6 & 1 & 20 & 152,460 & 536 & 70 \\
7 & 0.5 & 20 & - & 671 & 69 \\
8 & 0 & 20 & 381,670 & 763 & 69 \\
9 & 4 & 0 & 57,650 & 7 & 69 \\
10 & 1 & 0 & 132,180 & 107 & 71 \\
MEHEC & - & - & 373,600 & - & 70 \\
\hline
\end{tabular}

For samples $1-5$ and 9 , a $5 \mathrm{wt} \%$ polymer concentration was used. For samples 6-8, 10 and the reference, a $2 \mathrm{wt} \%$ polymer concentration was used

to transfer them into the capillary glass tube at a higher concentration.

A large addition of salt $(100 \mathrm{~g} / \mathrm{L})$ lowered the cloud point about $20^{\circ} \mathrm{C}$, sample 1 , compared to the unmodified reference MEHEC. A similar trend has been reported by Allahbash et al. for similar systems. They found that an addition of orthophosphate on silanized HPMC gels decreased both the gelatinization temperature and the cloud point of the studied solutions [15]. With a smaller addition of salt $(20 \mathrm{~g} / \mathrm{L})$, the effect was less pronounced and in some cases barely noticeable. For samples 2-5, the cloud point was lowered about $5-7^{\circ} \mathrm{C}$ and for samples $6-10$ it was almost unaffected and the effect here is more likely a result of the combination of a shorter chain length and salt addition, than salt addition alone. The results obtained with samples 8 and 9 support to some extent this since neither salt, nor a shorter chain length alone changed the cloud point more than about $1{ }^{\circ} \mathrm{C}$.

\section{Dynamic Mechanical Thermal Analysis}

The $T_{g}$-values, obtained using DMTA, are given in Table 6 . Obviously, the changes in molecular weight did not significantly affect the softening temperature of the material and no trend can be seen in the variation in $T_{g}$. The variation is quite small (being 5\% or less) and is mainly to be associated with experimental scatter. The measured $T_{g}$ (being mainly between 170 and $180^{\circ} \mathrm{C}$ ) are also in accordance with previously reported values for similar cellulose derivatives. Sakellariou et al. reported $T_{g}$-values of HPMC in the range of $169-180{ }^{\circ} \mathrm{C}$ depending on experimental conditions and technique used [16] and Karlsson et al. measured the $T_{g}$ by DMTA to be in the region $160-170{ }^{\circ} \mathrm{C}$, also for HPMCgrades [17].
Table $6 T_{g}$ of the modified MEHEC in the dry state

\begin{tabular}{lllll}
\hline Sample & $\mathrm{NaClO}(\mathrm{wt} \%)$ & $\mathrm{Na}_{2} \mathrm{SO}_{4}(\mathrm{~g} / \mathrm{L})$ & $M_{w}(\mathrm{~g} / \mathrm{mol})$ & $T_{g}\left({ }^{\circ} \mathrm{C}\right)$ \\
\hline 1 & 2 & 100 & - & 175 \\
2 & 4 & 50 & 55,290 & 176 \\
3 & 8 & 20 & 34,980 & 172 \\
4 & 4 & 20 & 55,380 & 168 \\
5 & 2 & 20 & - & 179 \\
6 & 1 & 20 & 152,460 & 174 \\
7 & 0.5 & 20 & - & 177 \\
8 & 0 & 20 & 381,670 & 178 \\
9 & 4 & 0 & 57,650 & 176 \\
10 & 1 & 0 & 132,180 & - \\
MEHEC & - & - & 373,590 & 175 \\
(refer- & & & & \\
ence) & & & & \\
\hline
\end{tabular}

\section{Foaming}

As given in the Experimental section, the foaming with the hot mould was performed with polymer concentrations in the range $5-20 \mathrm{wt} \%$, at temperatures of 180,200 or $220^{\circ} \mathrm{C}$ and with moulding times of 10 or $15 \mathrm{~min}$. It was difficult to visually assess the foaming ability of the different samples; thus only general observations will be commented on in the following. An indicator of whether the foaming ability was considered to be good or poor was if the expansion filled the entire mould, adapting to its cylindrical shape.

First it should be noted that all the samples foamed, at least to some extent, when the polymer concentration was low (5 wt \%). A general observation was that the use of sodium sulphate appeared to counteract the foaming. This was especially pronounced with samples 1 and 2 which contained the highest amounts of $\mathrm{Na}_{2} \mathrm{SO}_{4}(100$ and $50 \mathrm{~g} / \mathrm{L}$, respectively). The foams did not expand properly to fill the mould and the cell structure was non-uniform. The lowered cloud point might contribute to the reduction in foamability, but the influence of the salt on the interaction between the polymer molecules with regard to the foam formation is not fully understood at this point, thus further investigations would be necessary. The unmodified MEHEC did produce a foam at a polymer concentration of $5 \mathrm{wt} \%$, but when increasing the concentration (up to $10 \mathrm{wt} \%$ ), the foaming ability was quite drastically reduced and the obtained "foam" was compact. Actually, the foam structure obtained at concentration of $5 \mathrm{wt} \%$ was quite fragile. A similar observation was made with sample 8, which had a similar molecular weight as the unmodified MEHEC. Foams of a low density was obtained with a polymer concentration of $5 \mathrm{wt} \%$, as shown in Fig. 3 (optical) and 5 (ESEM), but an increase in the concentration, to $10 \mathrm{wt} \%$, increased the viscosity substantially and the 


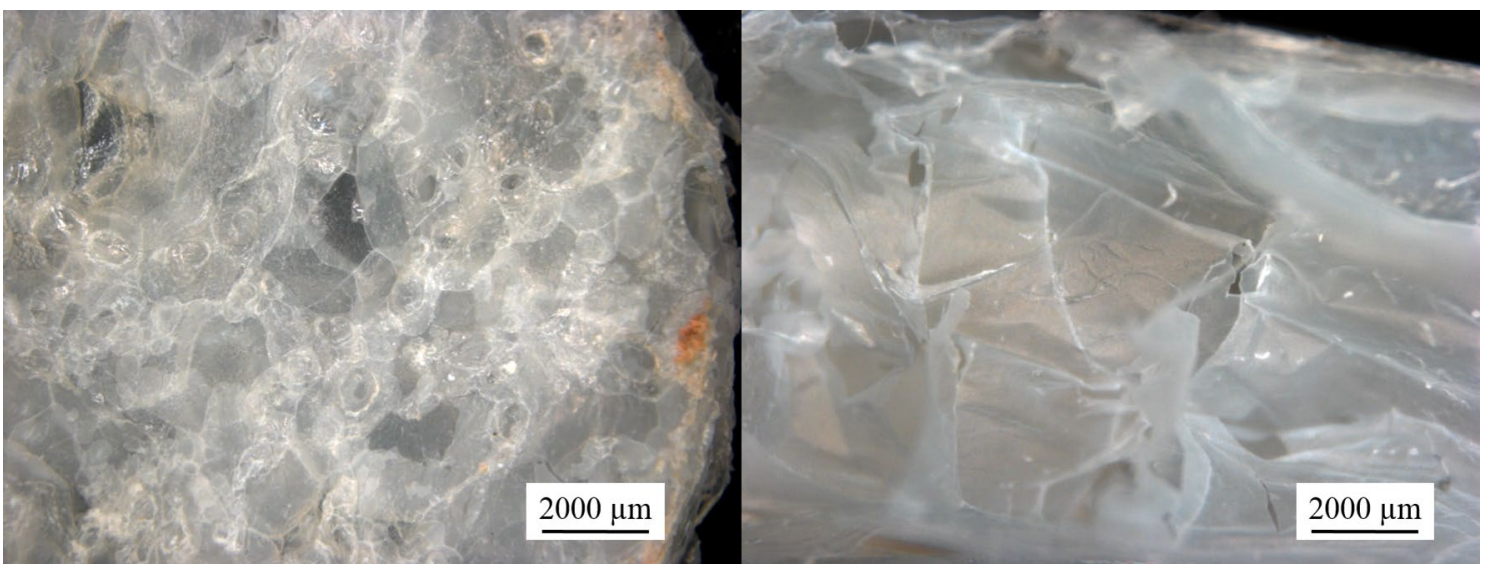

Fig. 3 Optical microscopy images of foam from sample 8 with a polymer concentration of $5 \mathrm{wt} \%$ and a foaming temperature of $180{ }^{\circ} \mathrm{C}$. The time in the hot mould was 10 min. Left: top view. Right: cross-sectional view

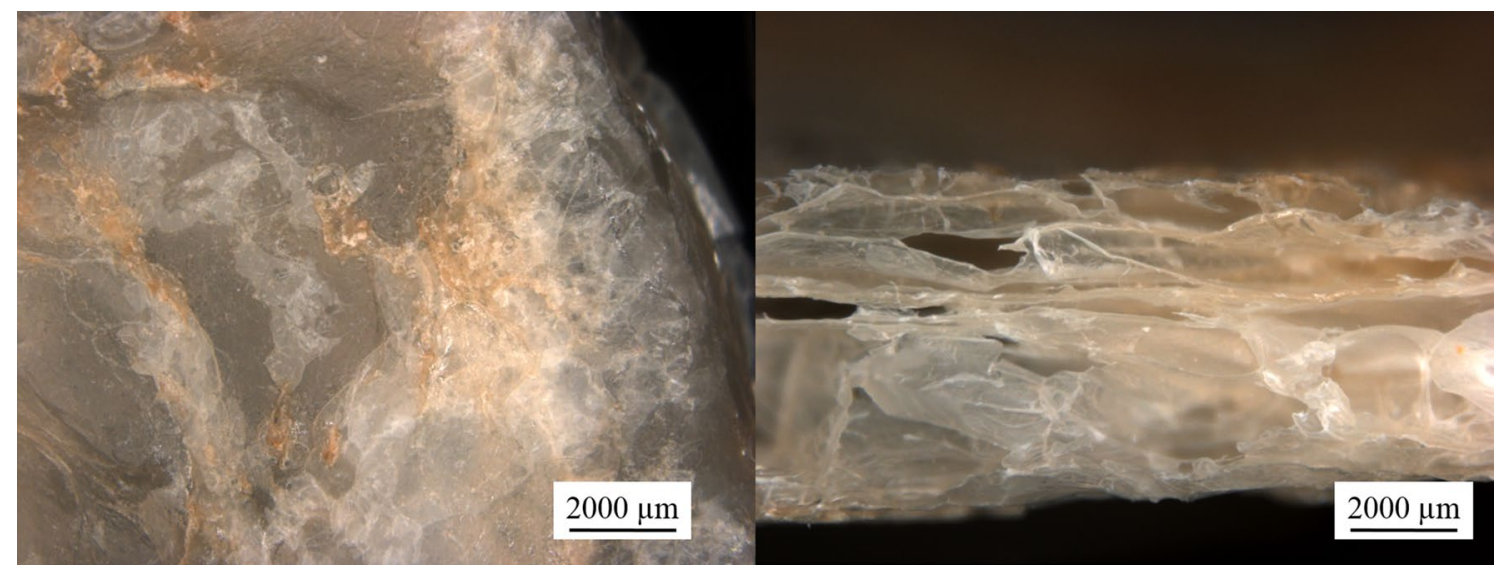

Fig. 4 Optical microscopy images of foam from sample 3 with a polymer concentration of $20 \mathrm{wt} \%$ and a foaming temperature of $220{ }^{\circ} \mathrm{C}$. The time in the hot mould was 10 min. Left: top view. Right: cross-sectional view

generated steam pressure was not sufficient to expand the structure to any significant extent.

The reduction in chain length (molecular weight) enabled an increase in the polymer concentration at which the cellulose ether form a mould of acceptable quality. This may not be surprising since such a reduction will reduce the viscosity and the elastic properties of the solution promoting the expansion by the available steam pressure. For example, foams could be formed from sample 3 at a polymer concentration of $20 \mathrm{wt} \%$ and this was the MEHEC-grade that the lowest molecular weight $\left(M_{w}=34,980 \mathrm{~g} / \mathrm{mol}\right)$, see Fig. 4 (optical) and 6 (ESEM).

It is obvious that with the used foaming technique using a hot mould, the polymer concentration had to be rather carefully adjusted with regard to the molecular weight of the MEHEC grade. In most cases (but not all), the chosen foaming temperature seemed to have a less pronounced influence on visual appearance of the foams than the polymer concentration. However, the slightly brownish colour of the foam shown in Fig. 4, indicates that the foaming temperature of $220{ }^{\circ} \mathrm{C}$ should probably not be exceeded, since some degradation of the polymer could start in this range.

As can be seen in Figs. 5 and 6, the cell structure of the foams is rather inhomogeneous. The structure seems to consist of mainly closed pores, but a number of open pores is also likely to be present. The cell-size is considered macroscopic as most of the pores are in the range of 100-500 $\mu \mathrm{m}$.

\section{Density of Foamed Samples}

Density is one of the most important characteristics of a foam. It was here measured for five of the more interesting foamed samples at different foaming temperatures, see 


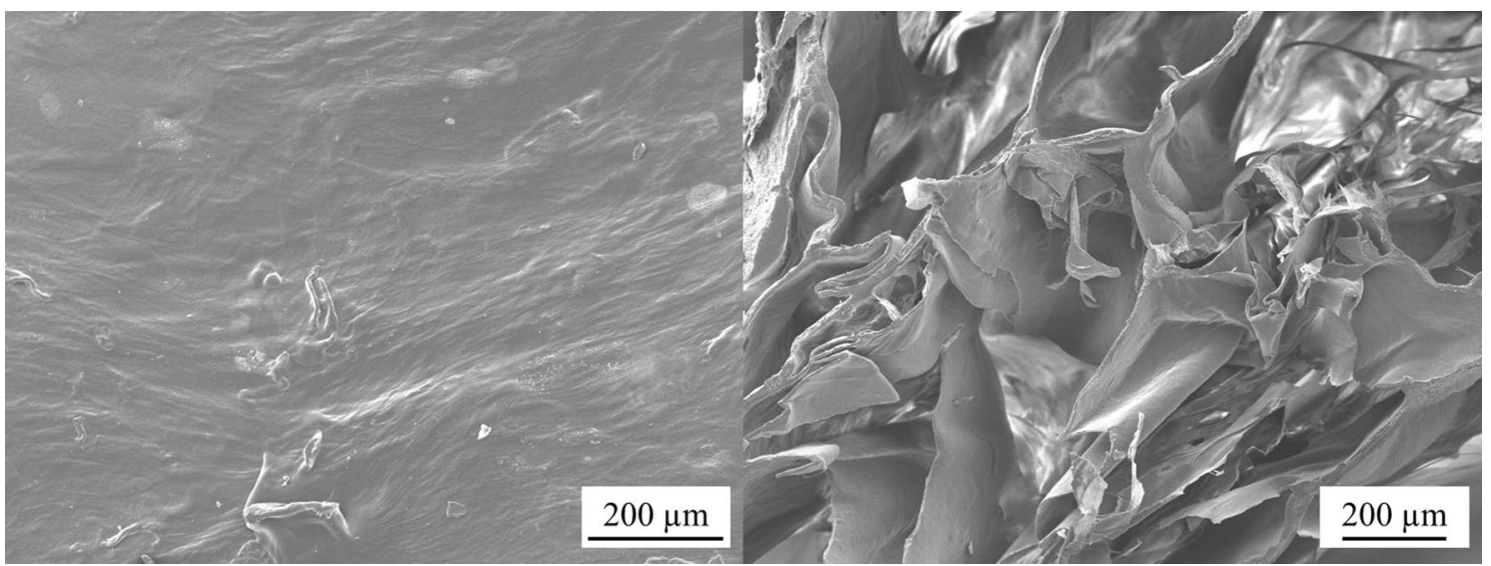

Fig. 5 ESEM images of foam from sample 8 (polymer concentration $5 \mathrm{wt} \%$, foaming temperature $180{ }^{\circ} \mathrm{C}$, time 10 min). Left: top view. Right: cross-sectional view

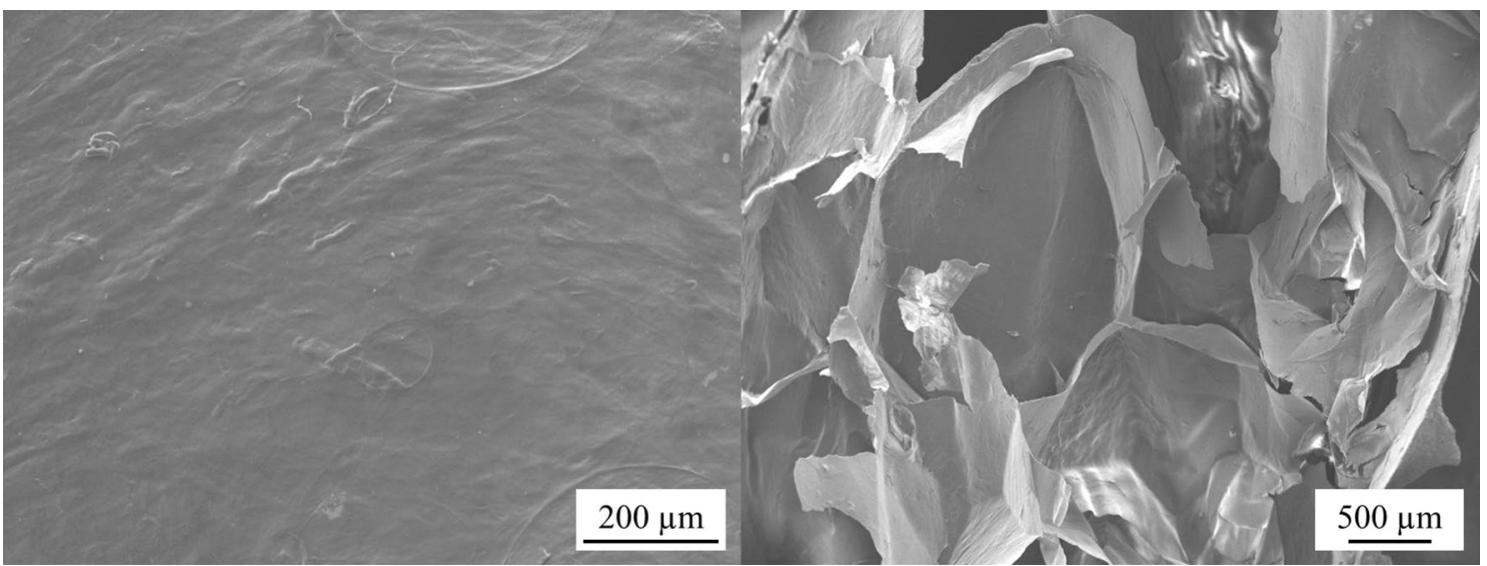

Fig. 6 ESEM images of foam from sample 3 (polymer concentration $20 \mathrm{wt} \%$, foaming temperature $220{ }^{\circ} \mathrm{C}$, time $10 \mathrm{~min}$ ). Left: top view. Right: cross-sectional view

Fig. 7. The numbers 1,2 , and 3 in the graph correspond to foaming temperatures of 180,200 or $220^{\circ} \mathrm{C}$, respectively. Depending on chain length of the polymer and the processing conditions, foams with densities ranging from 0.02 to $0.11 \mathrm{~g} / \mathrm{cm}^{3}$ were obtained with these modified MEHEC samples. To put these values into perspective, foams made from polystyrene (expanded polystyrene, EPS) generally have densities between 0.01 and $0.05 \mathrm{~g} / \mathrm{cm}^{3}$ and polyethylene (PE) foams usually have a density in the range of 0.025 to $0.33 \mathrm{~g} / \mathrm{cm}^{3}$ [18]. One specimen in Fig. 7 exhibits a density which is clearly higher than that of the others. This is sample 3 foamed at a concentration of $20 \mathrm{wt} \%$ and at the lowest temperature. Its higher density is probably a reflection of the higher viscosity of the solution at these conditions which counteracts the expansion by the generated steam.

\section{Discussion}

An amount of $20 \mathrm{~g} / \mathrm{L}$ of $\mathrm{Na}_{2} \mathrm{SO}_{4}$ was used in the majority of the experiments to facilitate the mixing of the components and the filtration of the polymeric slurry. An initial high concentration of $100 \mathrm{~g} / \mathrm{L}$ did not give any substantial benefits in this respect (compared to a lower concentration). Trials with no added $\mathrm{Na}_{2} \mathrm{SO}_{4}$ also resulted in a reduction of the molecular weight, however, the time to filter the slurry was increased significantly and the powder obtained after drying had agglomerated into hard pieces which were difficult to re-disperse. The addition of a small amount $(20 \mathrm{~g} / \mathrm{L})$ of $\mathrm{Na}_{2} \mathrm{SO}_{4}$ was therefore used to improve the filtering and promote the dispersion of the polymer.

The foaming mechanism of the aqueous MEHEC solutions is not fully understood and further investigations of 


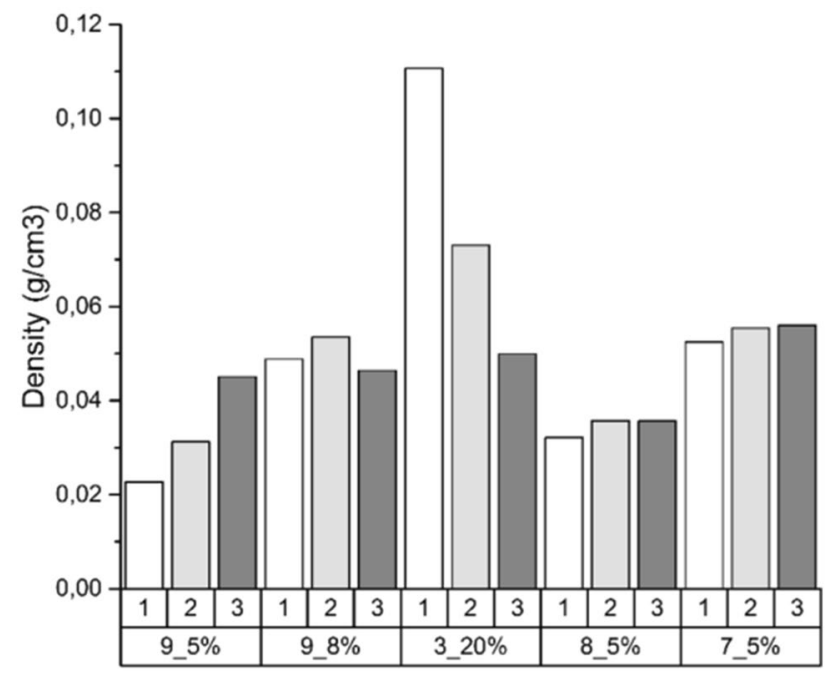

Fig. 7 The apparent density for some selected foams of modified MEHEC. The numbers 1,2 , and 3 in the graph correspond to foaming temperatures of 180,200 or $220^{\circ} \mathrm{C}$, respectively

the water evaporation and the thermal stabilization of the foams is desired. However, the foaming of aqueous HPMC solutions has been previously studied [7], and the foaming mechanism in case of the MEHEC system is believed to be of a similar kind. Like HPMC, MEHEC is clouding and exhibits a thermal gelation behaviour at temperatures below $100{ }^{\circ} \mathrm{C}$. The formation of a strong gel-network is believed to be of importance for the later preservation of the foam structure during the extensive water evaporation (80-95\% water) as the temperature is increased. However, the network strength (or the solution viscosity) should not be too high since this would suppress the foaming caused by the steam formation. In general, the polymers of a lower average molecular weight exhibited, as already stated, a better foaming ability. It is likely that the corresponding decrease in solution viscosity enables an improved expansion of the structure when using water (steam) as the blowing agent. However, it was noted that the samples which contained a higher amount of added $\mathrm{Na}_{2} \mathrm{SO}_{4}$ during the chain shortening reaction exhibited a poorer foaming ability than those with a lower addition of the salt. The detailed reasons for the negative effects of the sodium salt are not clear at this point, although it is likely that addition of the salts affects the water structure and consequently the interactions between the polymer molecules and the water, leading to the observed behaviour. The lowering of the cloud point when adding larger amounts of salt might be a contributing factor here, but this is not sufficiently clarified. The increase in solution viscosity when adding $\mathrm{Na}_{2} \mathrm{SO}_{4}$ can also play a role in this context.

The window for foaming seems in a sense to be quite narrow for these types of modified cellulose ethers. The molecular weight (chain length) controls the polymer concentration that can be used, at least with the foaming method used here. The polymer content and the average molecular chain length appear, to some extent, to be of more importance for the final structure than the foaming temperature and time. The temperature should however still be held within a reasonable range to avoid degradation of the sample. A further tailoring of the processing parameters along with a possible addition of other blowing agents could be useful in attempting to produce foams of a more uniform pore-size.

\section{Conclusions}

To summarize the findings from the chain reduction trials, it can be concluded that $\mathrm{NaClO}$ effectively reduced the average molecular weight of the polymer chains. This was seen both in the rheology measurements and was confirmed by the SEC-measurements.

The foaming of the MEHEC was improved by a shorter chain length in the sense that the lowering of the molecular weight allowed for an increase in the polymer concentration when foaming the polymers. From a technical point of view, this is of considerable importance. The observed behaviour is likely to be associated with the decreased viscosity of the polymer solutions when reducing the molecular weight. The negative effects on the foaming of adding $\mathrm{Na}_{2} \mathrm{SO}_{4}$ should be studied in more detail to clarify the underlying mechanisms.

The measurements of the apparent density showed that some of the foams exhibited densities within the same range as some commercial foams. This seems promising for further development of MEHEC foams.

Acknowledgements The funding from the Swedish Research Council Formas is gratefully acknowledged along with the contribution from Akzo Nobel who let us perform experiments in their laboratory facilities. Thanks to Anette Larsson, Gunnar Westman, Linda Härdelin, Filip Nylander, Marco Berta and all other members within the SmartFoam project for interesting, helpful discussions on laboratory equipment and interpretation of results.

Open Access This article is distributed under the terms of the Creative Commons Attribution 4.0 International License (http://creativeco mmons.org/licenses/by/4.0/), which permits unrestricted use, distribution, and reproduction in any medium, provided you give appropriate credit to the original author(s) and the source, provide a link to the Creative Commons license, and indicate if changes were made.

\section{References}

1. Statista PlasticsEurope (PEMRG) (2016) Global plastic production from 1950 to 2015 (in million metric tons). https://www. 
statista.com/statistics/282732/global-production-of-plastics-since -1950/. Accessed 30 Dec 2016

2. Lackner M (2015) Bioplastics. In: Kirk RE, Othmer DF (eds) Kirk-Othmer encyclopedia of chemical technology. Wiley, New York, pp. 1-41

3. Huang Y, Zhu C, Yang J, Nie Y, Chen C, Sun D (2014) Recent advances in bacterial cellulose. Cellulose 21(1):1-30

4. Mihranyan A (2011) Cellulose from cladophorales green algae: from environmental problem to high-tech composite materials. J Appl Polym Sci 119(4):2449-2460

5. Poletto M, Ornaghi Júnior HL, Zattera AJ (2014) Native cellulose: structure, characterization and thermal properties. Materials 7:6105-6119

6. Klemm D, Heublein B, Fink H, Bohn A (2005) Cellulose: fascinating biopolymer and sustainable raw material. Angew Chem Int Ed 44(22):3358-3393

7. Karlsson K, Schuster E, Stading M, Rigdahl M (2015) Foaming behavior of water-soluble cellulose derivatives: Hydroxypropyl methylcellulose and ethyl hydroxyethyl cellulose. Cellulose 22(4):2651-2664

8. Kjøniksen A, Knudsen K, Nyström B (2005) Phase separation and structural properties of semidilute aqueous mixtures of ethyl (hydroxyethyl) cellulose and an ionic surfactant. Eur Polymer J 41(9):1954-1964

9. Ali M, Kumar D, Al-Lohedan H (2014) Salt effect on the cloud point phenomenon of amphiphilic drug-hydroxypropylmethyl cellulose system. J Chem 2014. https://doi.org/10.1155/2014/29397 2

10. Li J, Bai D, Chen B (2009) Effects of additives on the cloud points of selected nonionic linear ethoxylated alcohol surfactants. Colloids Surf A 346(1):237-243
11. Gómez-Ordóñez E, Jiménez-Escrig A, Rupérez P (2012) Molecular weight distribution of polysaccharides from edible seaweeds by high-performance size-exclusion chromatography (HPSEC). Talanta 93:153-159

12. Potthast A, Radosta S, Saake B, Lebioda S, Heinze T, Henniges U, Isogai A, Koschella A, Kosma P, Rosenau T, Schiehser S, Sixta H, Strlič M, Strobin G, Vorwerg W, Wetzel H (2015) Comparison testing of methods for gel permeation chromatography of cellulose: coming closer to a standard protocol. Cellulose 22(3):1591-1613

13. Sjöqvist M, Gatenholm P (2007) The effect of water content in potato amylopectin starch on microwave foaming process. J Polym Environ 15(1):43-50

14. Joshi SC (2011) Sol-Gel behavior of hydroxypropyl methylcellulose (HPMC) in ionic media including drug release. Materials 4(10): 1861-1905

15. Allahbash S, Nicolai T, Chassenieux C, Tassin J, Benyahia L, Weiss P, Rethore G (2015) Interplay of thermal and covalent gelation of silanized hydroxypropyl methyl cellulose gels. Carbohydr Polym 115:510-515

16. Sakellariou P, Rowe R, White E (1985) The thermomechanical properties and glass transition temperatures of some cellulose derivatives used in film coating. Int J Pharm 27(2-3):267-277

17. Karlsson K, Kádár R, Stading M, Rigdahl M (2016) Processing window for extrusion foaming of hydroxypropyl methylcellulose. Cellulose 23(3):1675-1685

18. Biron M (2013) Detailed accounts of thermoplastic resins. In: Thermoplastics and thermoplastic composites. William Andrew, Oxford 